\title{
Ölçümleri Az Olan Kıyı Bölgelerinde Yağışın Yerel Dağılımının Belirlenmesi: Doğu Karadeniz Bölgesi
}

\author{
Ebru ERIŞ̧ ${ }^{1}$ \\ Necati AĞIRALİOĞLU ${ }^{2}$
}

ÖZ

Yağışın alandaki dağılımının belirlenmesi, hidrolojik uygulamaların ve su kaynaklarının doğru değerlendirilmesi açısından büyük önem taşır. Özellikle dağlık ve/veya kıyı bölgelerde hem orografiyi hem de kıyı etkilerini yağışın dağılımını belirlemede hesaba katmak gerekebilir. Bu gerekliliği, dağlık bölgelerde yağış gözlem istasyonlarının az ve düzensiz olması zorlaştıır. Bu çalışmada da, orografik yağış özelliği gösterdiği bilinen ve sınırlı sayıda yağış gözlem istasyonuna sahip Doğu Karadeniz Bölgesinin kıyı kesimi için yağış dağılımının belirlenmesi amaçlanmıştır. Çalışma, Doğu Karadeniz Bölgesinin kıyı kesimine ait yamaçlardaki yağış dağılımının temsilinde su dengesinin, kıyı ve vadilerdeki yağı̧s dağılımının temsilinde ise regresyon denklemlerinin birleştirilerek kullanılması açısından bir ilktir.

Anahtar Kelimeler: Yağış dağılımı, Doğu Karadeniz Bölgesi, eşyağış haritası.

\section{ABSTRACT \\ Determination of Spatial Distribution of Precipitation on Poorly Gauged Coastal Regions: Eastern Black Sea Region}

Determination of spatial distribution of precipitation has an importance in terms of hydrological applications and water resources assessment. Particularly, the effects of orography and coastline on precipitation distribution should be taken into account in mountainous and/or coastal regions. This necessity is complicated by the limited number of rain gauges which have also a nonhomogenous distribution. In this study, it is aimed to determine the spatial distribution of precipitation for the coastal part of the Eastern Black Sea Region. It can be said that this study is the first in terms of combination of precipitation distribution on both hillside and coastal part by using two different approaches. One of these approaches is the water balance that reflects the precipitation distribution on hillside. The other one depends on the regression equations which explains the precipitation variability on coastline and valleys, for the coastal part of the Eastern Black Sea Region.

Keywords: Precipitation distribution, Eastern Black Sea Region, isohyetal map.

Not: Bu yaz1

- $\quad$ Yayın Kurulu'na 24.11.2014 günü ulaşmıştır.

- 31 Mart 2017 gününe kadar tartışmaya açıktır.

1 Ege Üniversitesi, İnşaat Mühendisliği Bölümü, İzmir - ebru.eris@ege.edu.tr

2 İstanbul Teknik Üniversitesi, İnşaat Mühendisliği Bölümü, İstanbul - necati@itu.edu.tr 
Ölçümleri Az Olan Kıyı Bölgelerinde Yağışın Yerel Dağıllımının ...

\section{GíRiş̧}

Yağıs hidrolojik çevrimin en önemli girdisi olduğundan, alandaki dağılımının belirlenmesi de su kaynaklarının doğru değerlendirilmesi açısından önem kazanmaktadır. Özellikle yağış gözlem istasyonlarının az olduğu ve homojen olarak dağılmadığı dağlık ve kıyı bölgelerde yağış dağılımın belirlenmesi hayli güçtür. Dağlık bölgelerde çoğu zaman mevcut yağış istasyonları üzerinden kurulan modeller yağışın daha az tahmin edilmesine yol açmaktadır. Kıyı bölgelerde ise denizden gelen nemin ve kıyı topografyasının göz ardı edilmemesi gerekir.

Yağışın alandaki dağılımını belirleyebilmek için kullanılan metotlar, grafik, nümerik ve topografik olmak üzere üç ana grupta toplanmaktadır [1]. Literatürde Thiessen çokgeni gibi teknikleri içeren grafik metotlarla ilgili çalışmalar [2, 3] olduğu gibi, Ters Mesafe Ağırlıklı Enterpolasyon Yöntemi, Lokal Polinom, Radyal Tabanlı Fonksiyon, Kriging vb. yöntemleri içeren nümerik metot çalışmaları da bulunmaktadır $[4,5,6,7,8,9]$. Topografik metotlar ise, bir bölgedeki nokta ölçümleri ile bu bölgeye ait yükseklik, eğim, bakı, rüzgar yönü ve hızı gibi bir takım coğrafik ve topoğrafik özelliklerin ilişkisini kapsamaktadır $[1,10,11,12$, $13,14,15,16,17]$.

Öte yandan, orografik etkiler gösteren dağlık bölgelerde yağış dağılımının daha doğru belirlenmesi açısından su dengesi gibi farklı yaklaşımlar da uygulanmaktadır $[18,19,20]$. $\mathrm{Bu}$ yaklaşımdaki amaç, genellikle düşük yükseklikte ve/veya yerleşim bölgeleri yakınına kurulan ve bu sebeple orografik yağış özelliğini tam olarak yansıtamayan mevcut gözlem istasyonlarının verilerini kullanmak yerine, akım, buharlaşma, sızma gibi diğer hidrolojik çevrim elemanlarından yararlanarak yağışın tahmin edilmesini sağlamaktır.

$\mathrm{Bu}$ çalışmada da, Doğu Karadeniz Bölgesi'nin kıyı kesiminde yağış dağılımının belirlenmesi amaçlanmıştır. Bu nedenle bölgenin yağış dağılımı üzerinde, kıyı şekli ile birlikte enlem, boylam, yükseklik, denizden mesafe gibi coğrafik ve topoğrafik özelliklerin etkisinin incelendiği ve bu etkilerin regresyon analizi yardımıyla denklemlere dönüştürüldüğü Eriş ve Ağıralioğlu [21, 22] çalışmalarından da yararlanılmıştır. Öncellikle; bu çalışmalardan alınan regresyon denklemleri kullanılarak bölgenin eşyağış haritası oluşturulmuştur. Sözü geçen bu eşyağış haritası, Kriging yöntemi ile elde edilen eşyağış haritası ile karşılaştııılmış ve ayrıca haritaların doğruluğu uzun dönem akış katsayıları ile kontrol edilmiştir. Her bir havza için ayrı ayrı bulunan akış katsayıları neticesinde yağış gözlem verileri kullanılarak kurulan modelin ya da Kriging gibi klasik bir yöntemin iyi sonuç vermediği anlaşılarak daha iyi bir yağış dağılım tahmini için su dengesi yaklaşımı uygulanmıştır. Su dengesi metoduyla bulunan dağılımın yamaçları ve yüksek yerleri temsil ettiği, önceden gözlem verileri kullanılarak bulunan regresyon denklemlerinin de kıyı ve vadi kesimi daha iyi temsil ettiği kabul edilerek; bu iki sonuç birleştirilip yeni bir eşyağış haritası hazırlanmıştır. Düzeltilmiş eşyağış haritasının bölgenin yağış dağılımını belirlemede daha iyi bir sonuç verdiği düşünülmektedir.

\section{CALISMA BÖLGESİ VE VERILER}

Yağış dağılımının belirlenmesinde, çalışma bölgesi olarak Doğu Karadeniz Bölgesinin kıyı kesimi kullanılmıştır. Bölgenin kıyı kesimi; Karadeniz kıyı şeridi ile Doğu Karadeniz dağları arasında kalan bölge olarak tanımlanabilir. Bilindiği üzere Doğu Karadeniz dağları 
kıyıya paralel uzanmakta, yer yer 3000 m’yi aşan yüksekliklere ulaşmaktadır. Doğu Karadeniz 1 lık ve nemli bir iklime sahip olup kışın kar yağışı görülmektedir. Bölgede genellikle yılın her ayında yağış yağmakla birlikte Mayıs-Haziran ile Ekim-Kasım aylarında daha çok, Temmuz ayında en az yağış yağmaktadır. Fakat yüksek yerlerde kışın yağan kar yağışları bahar ve yaz aylarında eridiği için genellikle en çok akış Mayıs ayında, en az akış Şubat ayında meydana gelmektedir. Kıyı bölgesindeki ortalama sıcaklık $14-15^{\circ} \mathrm{C}$ ve ortalama yağış ise $1000 \mathrm{~mm}$ 'den fazladır. Bölgedeki hakim rüzgar yönü rüzgar gülünün kuzey-batı diliminde oluşmaktadır [23, 24].

Çalışmada 38 Yağış Gözlem İstasyonuna (YGİ) ait ortalama yıllık yağış verisi, 40 Akım Gözlem İstasyonuna (AGİ) ait ortalama yıllık akım verisi kullanılmıştır. YGİ ve AGİler ile ilgili bilgiler ve konumları Tablo 1, 2 ve Şekil 1'de görülmektedir. İstasyonlar yorum kolaylığı açısından batıdan doğuya doğru numaralandırılmıştır. YGİ yükseklikleri $6 \mathrm{~m}$ ile $1700 \mathrm{~m}$ arasında değişmekte olup $1700 \mathrm{~m}$ 'den sonra yağış istasyonu bulunmamaktadır. AGİ yükseklikleri ise $17 \mathrm{~m}$ ile $1450 \mathrm{~m}$ arasında değişmekte olup AGİ drenaj alanı büyüklükleri yaklaşı $66 \mathrm{~km}^{2}$ ve $835 \mathrm{~km}^{2}$ arasındadır. Evapotranspirasyon hesabı için bölgedeki 23 istasyonunun (Tablo 1) sıcaklık, rüzgar hızı, nem, güneşlenme süresi, radyasyon vb. meteorolojik verileri kullanılmıştır.

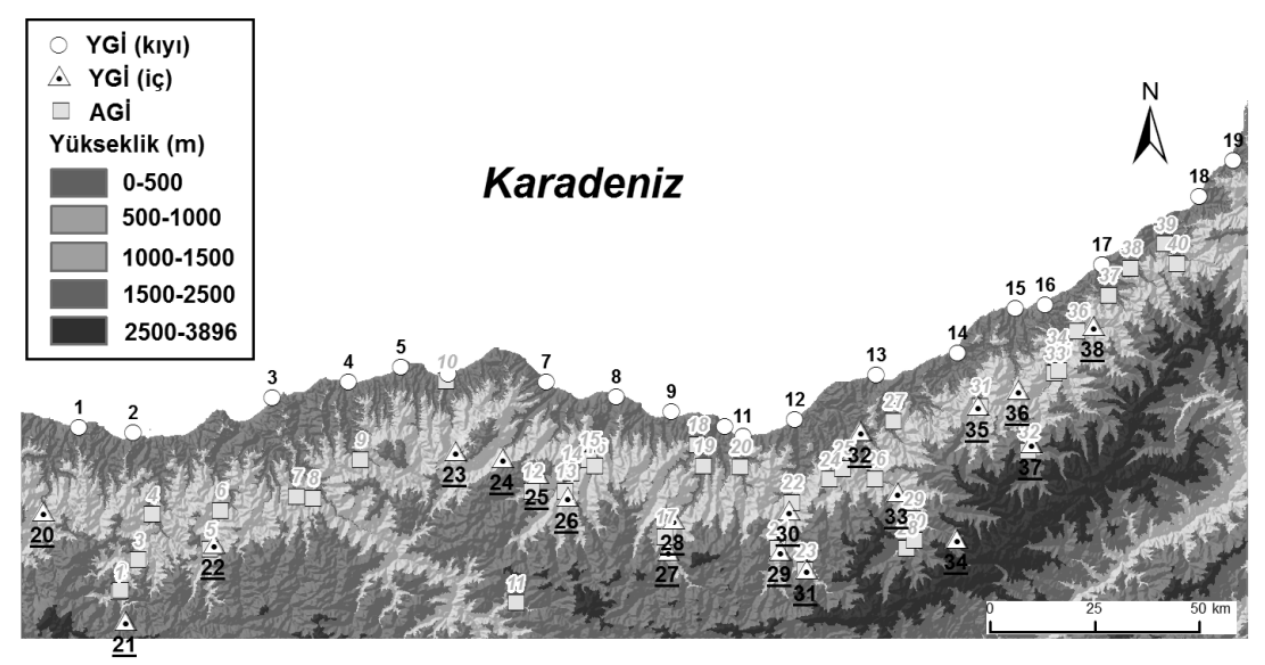

Şekil 1. Çalışma bölgesi ve yağlş istasyonları

Çalışmada kullanılan yağış verileri 1960-2005 yıllarını, akım verileri ise 1944-2006 yılların kapsamakla beraber eksik veriler de mevcuttur. Eksik verileri tamamlamak için komşu istasyonlardan yararlanarak regresyon denklemleri kurulmuştur. Yağış ve akım verilerinin homojenliği çift toplam eğrisi metodu ve trendi ise Mann-Kendall trend testi ile belirlenmiştir. Homojen olmayan ya da trend gösteren istasyonlarda, veri homojenleştirildikten ve trend çıarıldıktan sonraki değerler; gözlenen orijinal değerlerden en fazla \% 27 oranında farklı çıktığı için tüm istasyonlarda gözlem değerleri doğrudan kullanılmıştır. 
Ölçümleri Az Olan Kıyı Bölgelerinde Yağışın Yerel Dağıllımının ...

Tablo 1. Çalışmada kullanılan YGI

(*evapotranspirasyon hesabinda verileri kullanılan istasyonlar)

\begin{tabular}{|c|c|c|c|c|c|c|}
\hline \multicolumn{7}{|c|}{ Yağış Gözlem İstasyonları } \\
\hline $\begin{array}{l}\text { Sira } \\
\text { No }\end{array}$ & $\begin{array}{l}\text { YGİ } \\
\text { No }\end{array}$ & YGİ Adı & $\mathrm{X}$ & Y & $\begin{array}{l}\text { Yükseklik } \\
(\mathrm{m})\end{array}$ & $\begin{array}{l}\text { Gözlem } \\
\text { Periyodu }\end{array}$ \\
\hline 1 & 1453 & Bulancak* & 435457 & 4531639 & 10 & 1973-1997 \\
\hline 2 & 17034 & Giresun* & 448474 & 4530365 & 38 & $1960-2005$ \\
\hline 3 & 1460 & Tirebolu* & 481778 & 4538780 & 70 & $1975-2000$ \\
\hline 4 & 1299 & Görele & 500000 & 4542457 & 20 & 1960-1999 \\
\hline 5 & 1300 & Eynesil* & 512603 & 4546169 & 10 & 1963-1993 \\
\hline 6 & 1302 & Vakfikebir* & 523811 & 4544346 & 25 & $1960-2005$ \\
\hline 7 & 17626 & Akçaabat* & 547167 & 4542486 & 6 & $1960-2005$ \\
\hline 8 & 17037 & Trabzon & 564012 & 4538882 & 30 & $1975-2005$ \\
\hline 9 & 1471 & Arsin* & 577132 & 4535461 & 10 & 1963-1995 \\
\hline 10 & 1472 & Araklı* & 589799 & 4531904 & 10 & 1963-1996 \\
\hline 11 & 1473 & Sürmene & 594327 & 4529502 & 12 & $1960-1981$ \\
\hline 12 & 1475 & Of* & 606655 & 4533597 & 9 & 1960-1989 \\
\hline 13 & 17040 & Rize* & 626172 & 4544221 & 9 & $1960-2005$ \\
\hline 14 & 1312 & Çayeli & 645595 & 4549455 & 10 & $1960-1986$ \\
\hline 15 & 17628 & Pazar* & 659298 & 4560169 & 79 & $1975-2005$ \\
\hline 16 & 1156 & Ardeșen* & 666343 & 4561005 & 10 & 1965-1992 \\
\hline 17 & 1015 & Findıklı* & 680093 & 4570589 & 100 & $1960-2000$ \\
\hline 18 & 17042 & Нора* & 703345 & 4586759 & 33 & $1975-2005$ \\
\hline 19 & 818 & Kemalpaşa & 711502 & 4595512 & 75 & 1984-1999 \\
\hline 20 & $22-018$ & Sofulu & 426837 & 4511367 & 600 & $1980-2005$ \\
\hline 21 & $22-001$ & Tamdere & 446348 & 4485297 & 1700 & $1960-2005$ \\
\hline 22 & $22-020$ & Sinir & 467607 & 4503676 & 750 & $1984-2005$ \\
\hline 23 & 1623 & Tonya* & 525275 & 4525849 & 900 & $1963-1995$ \\
\hline 24 & 1624 & Düzköy* & 536517 & 4524046 & 850 & $1960-2003$ \\
\hline 25 & $22-017$ & Güzelyayla & 544967 & 4520393 & 1250 & $1979-2005$ \\
\hline 26 & 1626 & Maçka* & 552032 & 4514888 & 300 & $1960-1997$ \\
\hline 27 & $22-011$ & Kayaiçi & 576055 & 4502037 & 1050 & $1977-2002$ \\
\hline 28 & 1787 & Dağbası* & 577403 & 4509559 & 1450 & $1968-1998$ \\
\hline 29 & $22-016$ & Köknar & 602839 & 4502007 & 1218 & $1980-1997$ \\
\hline 30 & 1801 & Çaykara* & 604880 & 4511576 & 264 & $1960-1998$ \\
\hline 31 & 1962 & Uzungö1* & 609071 & 4497483 & 1110 & $1969-2005$ \\
\hline 32 & 1476 & Kalkandere* & 622103 & 4530518 & 400 & $1975-1996$ \\
\hline 33 & 1803 & İkizdere* & 630786 & 4515861 & 800 & $1975-1996$ \\
\hline 34 & $22-003$ & Sivrikaya & 645053 & 4504915 & 1650 & 1974-1995 \\
\hline 35 & 1480 & Kaptanpaşa* & 650060 & 4536588 & 525 & $1975-1996$ \\
\hline 36 & 22-009 & Hemsin & 659797 & 4540496 & 500 & 1963-1974 \\
\hline 37 & $22-013$ & Meydan & 662887 & 4527605 & 1100 & $1979-2002$ \\
\hline 38 & $22-019$ & Tunca & 677661 & 4555718 & 500 & $1983-2005$ \\
\hline
\end{tabular}


Ebru ERIŞ, Necati AĞIRALIOĞLU

Tablo 2. Çalıșmada kullanılan AGíler

\begin{tabular}{|c|c|c|c|c|c|c|c|c|}
\hline \multirow[b]{2}{*}{$\begin{array}{l}\text { Sira } \\
\text { No }\end{array}$} & \multicolumn{8}{|c|}{ Akım Gözlem İstasyonları } \\
\hline & $\begin{array}{l}\text { AGİ } \\
\text { No }\end{array}$ & AGİ Ad 1 & Akarsu & $\mathrm{X}$ & $\mathrm{Y}$ & $\begin{array}{c}\text { Drenaj } \\
\text { alan1 }\left(\mathrm{km}^{2}\right)\end{array}$ & $\begin{array}{l}\text { Yükseklik } \\
\text { (m) }\end{array}$ & $\begin{array}{l}\text { Gözlem } \\
\text { Periyodu }\end{array}$ \\
\hline 1 & 2236 & İkisu & Aksu & 445223 & 4492244 & 317.2 & 1037 & $1965-1974$ \\
\hline 2 & 22071 & İkisu & Aksu & 445532 & 4492765 & 292.7 & 1050 & 1986-1999 \\
\hline 3 & 22090 & Alancik & Aksu & 449695 & 4500044 & 470.2 & 750 & $1986-2004$ \\
\hline 4 & 2213 & Dereli & Aksu & 453193 & 4510906 & 713.0 & 248 & 1962-2004 \\
\hline 5 & 22080 & Sinırköy & Yağlı & 466875 & 4502569 & 296.9 & 750 & $1983-2005$ \\
\hline 6 & 22073 & Tuğlacık & Yağlı & 469448 & 4511808 & 397.9 & 400 & $1986-2006$ \\
\hline 7 & 22087 & Hasanşeyh & Gelevera & 487532 & 4515178 & 256.8 & 355 & 1984-2006 \\
\hline 8 & 22013 & Süttas1 & Kavraz & 491562 & 4514710 & 124.9 & 188 & $1970-2004$ \\
\hline 9 & 22058 & CücenKöprü & Görele & 502809 & 4523957 & 162.7 & 300 & 1980-2006 \\
\hline 10 & 2228 & Bahadırlı & Fol & 523443 & 4542680 & 191.4 & 17 & 1963-2002 \\
\hline 11 & 22084 & İkisu & Korum - Yağl1 & 540191 & 4489746 & 149.6 & 1450 & 1984-1999 \\
\hline 12 & 22088 & Ormanüstü & Maçka & 543960 & 4516409 & 150 & 770 & 1985-1999 \\
\hline 13 & 22061 & Ortaköy & Altın & 551927 & 4516460 & 261 & 450 & $1980-2002$ \\
\hline 14 & 2206 & Kanlıpelit & Değirmendere & 553256 & 4520756 & 708 & 257 & 1951-1989 \\
\hline 15 & 22086 & Öğütlü & Değirmendere & 557517 & 4523964 & 728.4 & 160 & 1984-2004 \\
\hline 16 & 22059 & Çiftdere & Galyan & 558911 & 4522341 & 121.5 & 250 & $1980-2005$ \\
\hline 17 & 22044 & Aytaş & Kara & 575591 & 4505532 & 421.2 & 510 & $1979-2005$ \\
\hline 18 & 22034 & Findiklı & Yanbolu & 583441 & 4527512 & 258.6 & 258.6 & 1970-2004 \\
\hline 19 & 2202 & Ağnas & Kara & 584879 & 4522532 & 635.7 & 78 & 1944-2002 \\
\hline 20 & 22053 & Ortakoy & Sürmene & 593617 & 4522268 & 173.6 & 150 & $1979-2006$ \\
\hline 21 & 22057 & Alçakköprü & Ögene & 602599 & 4502760 & 243 & 700 & $1979-2005$ \\
\hline 22 & 22052 & Ulucami & Solaklı & 606083 & 4513714 & 576.8 & 260 & 1979-2005 \\
\hline 23 & 22007 & Şerah & Haldizen & 609060 & 4497459 & 154.7 & 1170 & $1966-2001$ \\
\hline 24 & 22068 & Yenikoy & Baltacı & 615095 & 4519240 & 171.6 & 470 & $1982-2004$ \\
\hline 25 & 22066 & Cevizlik & Maki & 618217 & 4521849 & 115.9 & 400 & $1982-2001$ \\
\hline 26 & 2218 & Şimşirli & İyidere & 625873 & 4519354 & 834.9 & 308 & 1963-2004 \\
\hline 27 & 22082 & Kömürcüler & Salarha & 630293 & 4533126 & 83.3 & 250 & 1984-2002 \\
\hline 28 & 2233 & Tosköy & Tosköy & 633458 & 4502861 & 223.1 & 1296 & $1965-2002$ \\
\hline 29 & 2215 & Dereköy & Çamlıdere & 634927 & 4509890 & 445.2 & 942 & $1965-2002$ \\
\hline 30 & 22078 & Tosköy & Tosköy & 635353 & 4504561 & 284.3 & 1000 & 1986-2001 \\
\hline 31 & 22085 & Kaptanpaşa & Şenöz & 651039 & 4536732 & 231.2 & 400 & 1984-2006 \\
\hline 32 & 22074 & Çat & Hemsin & 662384 & 4525990 & 277.6 & 1100 & 1982-1999 \\
\hline 33 & 22062 & Konaklar & Hemsin & 668797 & 4544554 & 496.7 & 300 & 1980-2005 \\
\hline 34 & 2232 & Topluca & Firtına & 669079 & 4548541 & 762.3 & 233 & $1964-2002$ \\
\hline 35 & 22063 & Mikronköprü & Halo & 669784 & 4545317 & 239.2 & 325 & $1980-2004$ \\
\hline 36 & 22076 & Kemerköprü & Durak & 674187 & 4554678 & 302.2 & 230 & 1984-1997 \\
\hline 37 & 22072 & Ar1li & Arılı & 681674 & 4563223 & 92.15 & 175 & $1982-2005$ \\
\hline 38 & 22006 & Köprübaş1 & Abuçağlayan & 686891 & 4569712 & 156 & 60 & 1966-1999 \\
\hline 39 & 22049 & Başköy & Kapistre & 695072 & 4575544 & 186.2 & 75 & $1978-2006$ \\
\hline 40 & 22089 & Küçükköy & Balli & 698017 & 4570809 & 66.37 & 400 & $1985-2006$ \\
\hline
\end{tabular}


Ölçümleri Az Olan Kıyı Bölgelerinde Yağışın Yerel Dağıllımının ...

\section{EŞYAĞIŞ HARITTALARI}

\subsection{Yöntem}

Eşyağış haritalarının hazırlanmasında Ordinary Kriging yöntemi ve Regresyon Analizi (RA) yardımıyla çıkarılan denklemlerden yararlanılmıştır.

Kriging, Denklem 1'de görülen ağırlıkların $\left(\lambda_{i}\right)$, tahmin hatalarının ortalamasının sıfır ve varyansı en küçük olacak şekilde belirlenmesidir. Kriging matris formunda Denklem 2'deki gibi gösterilebilir. Matriste görülen $\gamma$ değerleri noktalar arasında uzaklığa ilişkin yarıvaryogram değerlerini, $\mu$ ise Lagrange sabitini göstermektedir. Yarıvaryogram ise Denklem 3 formülüyle hesaplanır.

$$
\begin{aligned}
& Z^{*}\left(x_{0}\right)=\sum_{i=1}^{N} \lambda_{i} Z\left(x_{i}\right) \\
& {\left[\begin{array}{ccccc}
\gamma_{11} & \gamma_{12} & \cdot & \gamma_{1 N} & 1 \\
\gamma_{21} & \gamma_{22} & \cdot & \gamma_{2 N} & 1 \\
\cdot & \cdot & \cdot & \cdot & \cdot \\
\gamma_{N 1} & \gamma_{N 2} & \cdot & \gamma_{N N} & 1 \\
1 & 1 & \cdot & 1 & 0
\end{array}\right]\left[\begin{array}{c}
\lambda_{1} \\
\lambda_{2} \\
\cdot \\
\lambda_{N} \\
\mu
\end{array}\right]=\left[\begin{array}{c}
\gamma_{01} \\
\gamma_{02} \\
\cdot \\
\gamma_{0 N} \\
1
\end{array}\right]} \\
& \gamma(h)=\frac{1}{2 N(h)} \sum_{i=1}^{N}(Z(x+h)-Z(x))^{2}
\end{aligned}
$$

Burada $Z(x)$ ve $Z(x+h) ; x$ ve $x+h$ noktalarındaki yağış değerlerini, $N(h)$ birbirinden $h$ kadar uzaklıktaki tüm veri çiftlerinin sayısını göstermektedir. Herhangi bir bölgede enterpolasyon için Kriging kullanılacaksa, çalışma bölgesindeki verilerden yararlanarak deneysel varyogram Denklem 3'e göre hesaplanır. Böylece, deneysel varyogram yardımıyla teorik modele ait parametreler belirlenebilir. Kriging yöntemiyle belirlenen ağırlıklar seçilen teorik varyogram fonksiyonuyla doğrudan ilişkilidir. Geoistatistikte sıkça kullanılan fonksiyonlar, gauss, üssel, küresel, logaritmik ve liner modellerdir.

\subsection{Uygulama}

Eşyă̆ıș haritaları Kriging ve regresyon olmak üzere iki farklı yöntemle hazırlanmıștır. Yağışın dağılımının belirlenmesinde kullanılan Ters Mesafe Ağırlıklı Enterpolasyon (Inverse Distance Weighted-IDW), Radyal Tabanlı Fonksiyon (Radial Basis FunctionRBF) gibi yöntemler bu çalışmada kullanılmışsa da; söz konusu yöntemlerin orografik özellik gösteren bölgelerde yetersiz kalması nedeniyle $[25,26]$ bulunan sonuçlara burada değinilmemiştir.

Haritaların hazırlanmasında daha önce Eriş ve Ağıralioğlu [21, 22] çalışmalarında, bölgedeki yağış dağılımı için bulunan regresyon denklemleri kullanılmıştır. Bahsi geçen bu regresyon denklemleri bölgedeki yağı̧̧ ile coğrafik/topografik değişkenlerin ilişsisinden 
yararlanılarak çıkarılmıştır. Bu denklemler, ayrıca kıyı şeklinin yağış üzerindeki etkisini temsil eden ve yeni bir değişken olarak sunulan kıyı açısını da içermektedir. Bu çalışmada regresyon analizinin ayrıntılarına girilmeyecek olup çıkarılan denklemler Denklem 4a ve 4b'de kıyı ve iç istasyonlar için ayrı ayrı verilmiştir.

$$
\begin{aligned}
& P=\beta_{o}+\beta_{1} A \\
& P=\beta_{o}+\beta_{1} Y+\beta_{2} A
\end{aligned}
$$

Bu bağıntılarda; $P$; yağış yüksekliğini, $Y$; enlem, $A$ ise kıyı açısını göstermektedir. $\beta^{\prime}$ lar ise regresyon katsayılarıdır.

İki farklı yönteme göre çıkarılmış eşyağış haritaları Şekil 2'de verilmiştir. Yöntemler hem çapraz doğrulama (kalibrasyon) hem de basit doğrulama (validasyon) ile kontrol edilmiştir. Çapraz doğrulamada söz konusu yöntem içerisinde yer alan ölçüm noktalarındaki değerler; çevresindeki değerlerle tahmin edilmiş ve daha sonra gerçek değerlerle karşılaştırılmıştır. Karşılaştırmalar Ortalama Hatanın Karesinin Karekökü (OHKK) ve Ortalama Mutlak Hata $(\mathrm{OMH})$ istatistiklerine göre değerlendirilmiştir. Basit doğrulamada ise rastgele seçilen 6 YGİ için modellerin validasyonu yapılmıştır (Tablo 3).

Tablo 3. Eşyağış haritalarının elde edilmesinde kullanılan yöntemlere ait kalibrasyon ve validasyon sonuçları

\begin{tabular}{cccc|cccc}
\hline \multicolumn{3}{c}{ Kalibrasyon } & \multicolumn{5}{c}{ Validasyon } \\
\hline $\begin{array}{c}\text { İstasyon } \\
\text { Türü }\end{array}$ & İstatistik & Kriging & Regresyon & $\begin{array}{c}\text { İstasyon } \\
\text { Adı }\end{array}$ & Ölçüm & $\begin{array}{c}\text { Tahmin } \\
\text { (Kriging) }\end{array}$ & $\begin{array}{c}\text { Tahmin } \\
\text { (Regresyon) }\end{array}$ \\
\hline $\begin{array}{c}\text { Kıyı } \\
\text { istasyonlar } \\
(16 \text { adet) }\end{array}$ & $R^{2}$ & 0.924 & 0.839 & Görele (4) & 1595.4 & 1511.1 & 1899.4 \\
& $O M K K$ & 167.27 & 227.02 & Sürmene (11) & 1181.4 & 1171.3 & 1045.8 \\
$\begin{array}{c}\text { İç } \\
\text { istasyonlar } \\
(16 \text { adet) }\end{array}$ & OHKK & 118.02 & 198.43 & Findıklı (17) & 2217.4 & 2075.2 & 2067.9 \\
\hline
\end{tabular}

İki farklı yöntemden çıkarılan haritalar birbirine benzemekte, determinasyon katsayıları ve validasyon sonuçları oldukça tatminkar gözükmektedir. Ancak bölgenin dağlık olduğu ve YGİ noktalarının çok olmaması ya da homojen dağılmaması nedeniyle çıkarılan eşyağış haritalarının ayrıca kontrol edilmesi gerekli görülmüştür. Haritaların doğruluğunu tespit etmek için yıllık akış katsayıları hesaplanmıştır. Buna göre ortalama yıllık akım verisi bulunan 40 AGİye ait drenaj havzaları için ortalama alan yağış değerleri çıkarılmış ve akış katsayısı hesabında kullanılmıştır. Sonuçlar Şekil 3'te görülmektedir.

Şekil 3’ten görüldüğü üzere, farklı yöntemlere göre bulunan eşyağış haritalarından çıkarılan ortalama alan yağışlarına göre bulunan akış katsayılarından önemli bir kısmı 1'den büyük ya da 1'e çok yakındır ki bu durum teorik olarak anlamsız görünmektedir. Aylık bazda kar 
Ölçümleri Az Olan Kıyı Bölgelerinde Yağışın Yerel Dağıllımının ...

erimesi ya da yer altı suyu beslenmesinden dolayı 1'den büyük çıkabilecek akış katsayılarının yıllık bazda 1'den büyük çıkması mümkün olmamaktadır. Bu durum akış katsayısı hesabında kullanılan ortalama alan yağışlarının doğru olmadığını düşündürmektedir. Bir başka deyişle YGïler, konumları nedeniyle orografik yağış̧ etkilerini temsil edememektedir. Çalışma bölgesi için doğru bir yăğı̧ dağılımı tespiti doğrudan mevcut YGiller üzerinden kurulan modellerle mümkün olamayacağından, farklı bir yaklaşım olarak su dengesinden yararlanarak yağı̧ dağılımının belirlenmesi yoluna gidilmiştir. Bu yaklaşımla ortalama yıllık akım ile gerçek evapotranspirasyon haritaları çıkarılmış ve beraberce değerlendirilerek yağı̧ dağılımına ulaşılmışıtır. Bölge özellikleri ve zaman ölçeği (yıllık) göz önüne alınarak akiferdeki net debi değişimi ihmal edilmiştir.

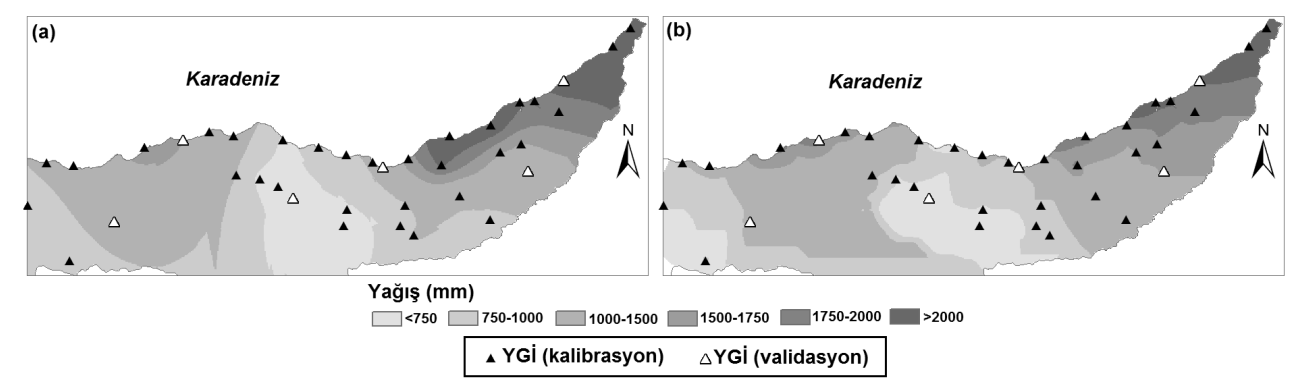

Şekil 2. Eşyăğı̧ haritaları (a) Kriging ve (b) Regresyon

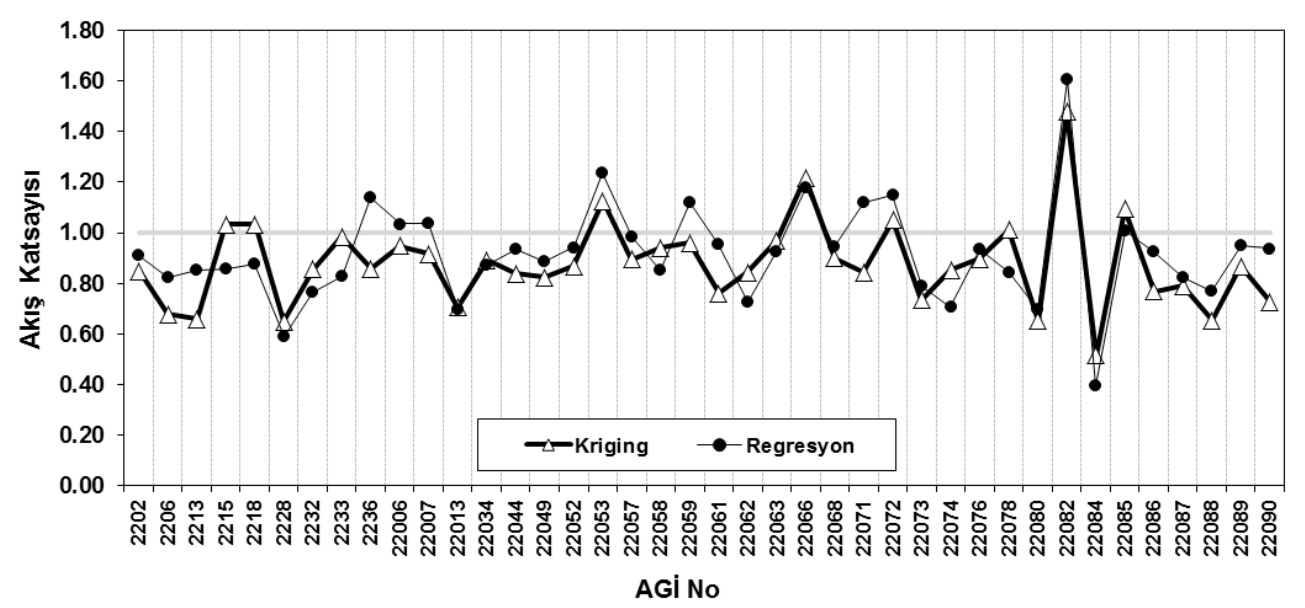

Şekil 3. AGİ havzalarına ait yıllık akış katsayıları 


\section{SU DENGESİ YAKLAŞIMI}

\subsection{Yöntem}

Yağış dağılımının belirlenmesinde su dengesi yöntemi uygulanmıştır (Denklem 5).

$\bar{P}=\bar{Q}+\overline{E T}+G$

Burada, $\bar{P}, \bar{Q}, \quad \overline{E T}$ sırasıyla uzun dönem ortalama yıllık yağış, akım ve evapotranspirasyonu göstermektedir. $G$ ise akiferdeki (sistemi besleyen veya beslenen) net debi değişimini ifade eder. Mevsim ve su tablası seviyelerine göre net debi değişimi $(G)$ pozitif veya negatif olabilir. Ancak uzun yıllar ortalaması alındığında bu değişimin etkisi ihmal edilebilmektedir [19]. Özellikle akifer alanları ihmal edilecek kadar küçük olan Doğu Karadeniz Bölgesindeki [27] söz konusu değişim, topografyasının aşırı derecede eğimli ve jeolojik yapısının genelde volkanik kayaç niteliğinde olmasına [28] bağlı olarak su bütçesi çalışmasında ihmal edilmiştir.

Akımın alan üzerinde enterpolasyonunda Huang ve Yang [29] çalışmasından yararlanılmıştır. Buna göre ortalama yıllık akım, akım yüksekliğine dönüştürülerek havza ağırlık merkezine yerleştirilmiş, daha sonra Kriging yöntemi yardımıyla alandaki dağı̆ımı bulunmuştur. Akım yüksekliği, yağış gibi bir noktayı temsil etmekten ziyade üzerinde kalan alanı temsil ettiğinden dolayı ağırlık merkezine yerleştirilmiştir.

Öte yandan, evapotranspirasyonun alandaki dağılımını belirlemek için öncellikle gerçek (muhtemel) evapotranspirasyon değerleri, Turc [30]-Pike [31] formülüne göre hesaplanmıştır. Turc-Pike gerçek evapotranspirasyon modeli aşağıdaki şekilde gösterilebilir.

$$
\frac{M E T}{P E T}=\frac{(P / P E T)}{\sqrt{1+\left(\frac{P}{P E T}\right)^{2}}}
$$

Burada, MET, PET ve $P$ sirasiyla gerçek (muhtemel) ve potansiyel evapotranspirasyon, ortalama yıllık yağıştır. Modelde bulunan potansiyel evapotranspirasyon FAO-56 PenmanMonteith [32] denklemi ile bulunmuştur (Denklem 7).

$$
E T_{0}=\left[\frac{0.408 \Delta\left(R_{n}-G\right)+\gamma\left(\frac{900}{T+273}\right) u_{2}\left(e_{s}-e_{a}\right)}{\Delta+\gamma\left(1+0.34 u_{2}\right)}\right]
$$

Burada; $E T_{0}$ : Referans evapotranspirasyon (mm/gün), $R_{n}$ : bitki yüzeyindeki net radyasyon $\left(\mathrm{MJ} / \mathrm{m}^{2}\right.$ gün), G: zemin 1S1 değişim yoğunluğu ( $\mathrm{MJ} / \mathrm{m}^{2}$ gün), $T: 2 \mathrm{~m}$ yükseklikte günlük ortalama hava sıcaklığı $\left({ }^{0} \mathrm{C}\right), u_{2}: 2$ m yükseklikteki ortalama rüzgar hızı $(\mathrm{m} / \mathrm{s}), e_{s}$ : doymuş buhar basıncı $(\mathrm{kPa}), e_{a}$ : mevcut buhar basıncı $(\mathrm{kPa}), e_{s}-e_{a}$ : doymuş buhar basıncı açığı 
Ölçümleri Az Olan Kıyı Bölgelerinde Yağışıı Yerel Dağılımının ...

$(\mathrm{kPa}), \Delta=$ buhar basıncı eğrisinin eğimi $\left(\mathrm{kPa} /{ }^{\circ} \mathrm{C}\right)$ ve $\gamma$ : psikrometrik sabit $\left(\mathrm{kPa} /{ }^{0} \mathrm{C}\right)$ değerlerini göstermektedir.

\subsection{Uygulama}

Akım yüksekliği haritasının belirlenmesinde, 40 adet AGİye ait akım yüksekliği, yine bu havzalara ait ağırlık merkezlerine yerleştirilmiştir. Modelin validasyonu için rastgele 6 AGi seçilmiştir. Huang ve Yang [25] çalışmasından yararlanılarak Ordinary Kriging yöntemi uygulanmıştır. Uygulanan yönteme göre çıkarılan akım yüksekliği haritası Şekil 4'te ve validasyon aşamasına ait sonuçlar ise Tablo 4'te verilmiştir.

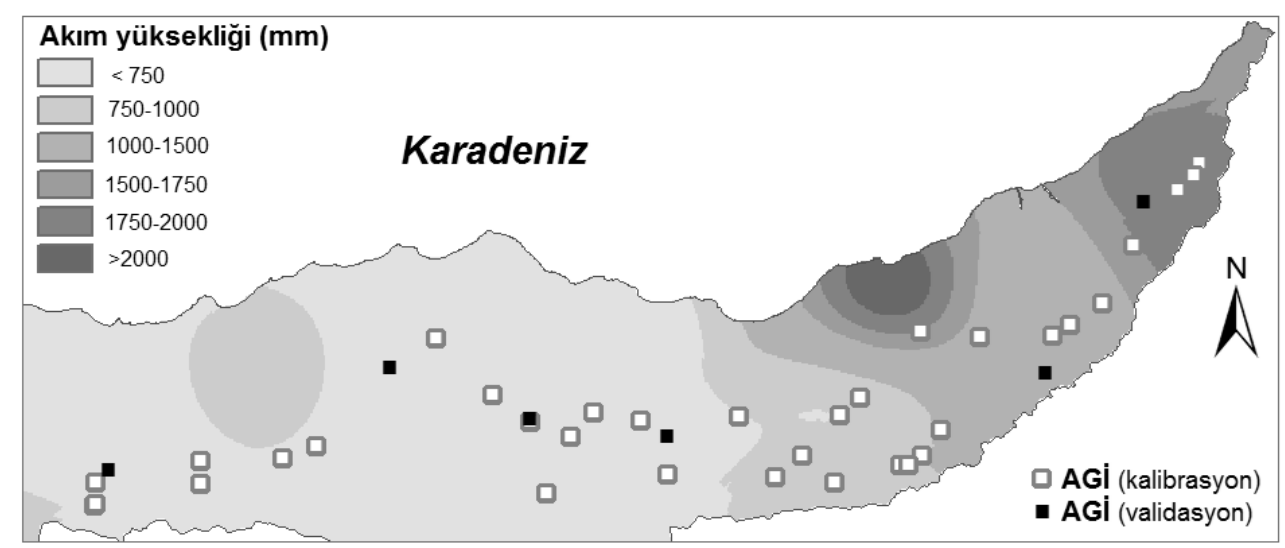

Şekil 4. Akım yüksekliği haritası

Tablo 4. Akım yüksekliği için validasyon sonuçları

\begin{tabular}{cccc}
\hline AGİ No & $\begin{array}{c}\text { Ölçüm debisi } \\
\left(\mathrm{m}^{3} / \mathrm{s}\right)\end{array}$ & $\begin{array}{c}\text { Tahmini akım yüksekliği } \\
(\mathrm{mm})\end{array}$ & $\begin{array}{c}\text { Tahmin debisi } \\
\left(\mathrm{m}^{3} / \mathrm{s}\right)\end{array}$ \\
\hline 2202 & 12.20 & 702.57 & 14.16 \\
2213 & 13.80 & 640.43 & 14.48 \\
22058 & 5.68 & 651.27 & 3.36 \\
22072 & 6.32 & 1722.26 & 5.03 \\
22074 & 8.79 & 965.31 & 8.50 \\
22086 & 12.85 & 504.50 & 11.65 \\
\hline
\end{tabular}

Evapotranspirasyon haritası için bölgede büyük ve küçük klima istasyonlarına ait minimum, maksimum sıcaklıklar, ortalama rüzgar hızı, ortalama nem, güneșlenme süresi, global güneş radyasyonu Meteoroloji Genel Müdürlüğü'nden (MGM) temin edilerek potansiyel ve muhtemel evapotranspirasyon değerleri sırasiyla FAO-56 Penman-Monteith ve Turc-Pike formülüyle hesaplanmıştır, bulunan değerler Şekil 5 'te gösterilmiştir. 


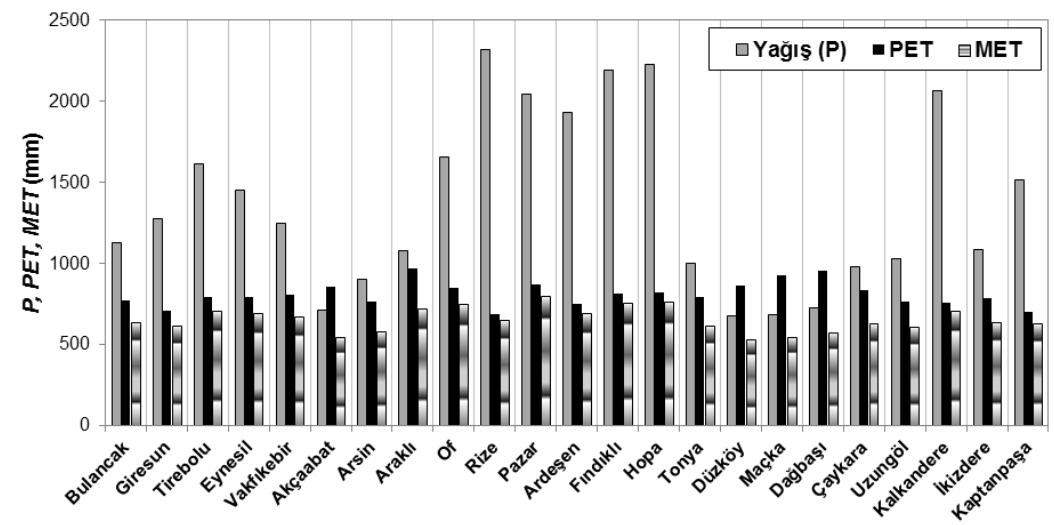

Şekil 5. Hesaplanan potansiyel evapotranspirasyon (PET), muhtemel evapotranspirasyon (MET) ve ölçülen yă̆ıs değerleri

Kriging yöntemi bir kez daha kullanılarak evapotranspirasyon haritası elde edilmiştir. Veri sayısı çok olmadığından validasyon aşaması için veri ayrılmamıştır. Çapraz doğrulama sonuçları ile yetinilmiştir. Turc-Pike formülüne göre hesaplanan muhtemel evapotranspirasyon haritası ise Şekil 6'da verilmiştir.

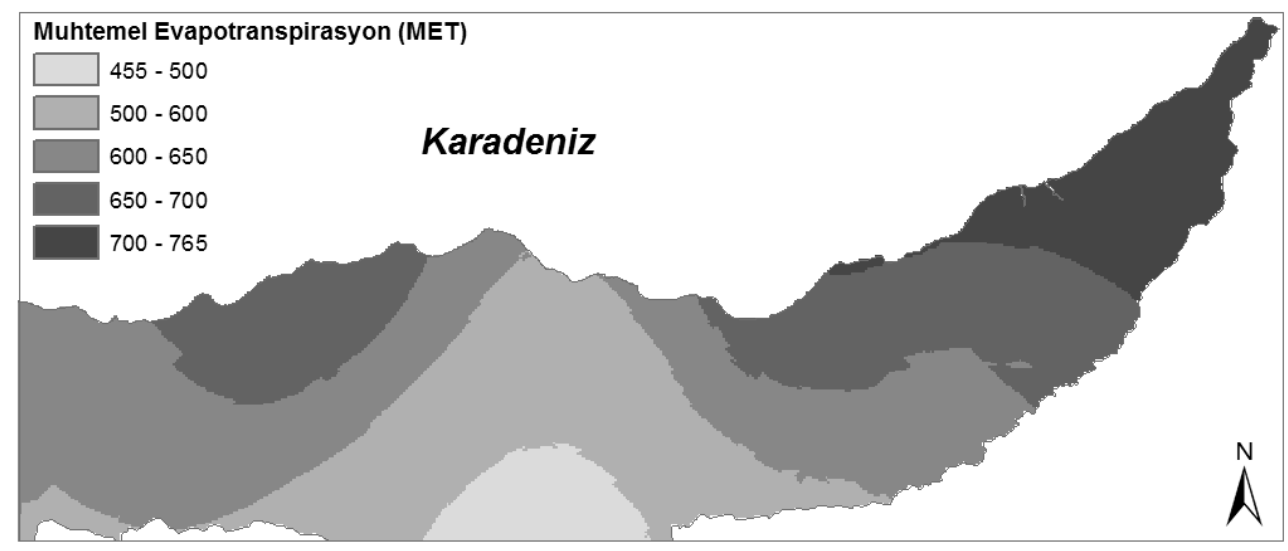

Şekil 6. Muhtemel Evapotranspirasyon (MET) haritast

Elde edilen akım yüksekliği ve evapotranspirasyon haritaları beraberce değerlendirilerek Şekil 7'de görülen yağış haritası elde edilmiștir. Anlaşılacağı üzere bu eşyağış haritasının elde edilmesinde herhangi bir YGİ kullanılmamış olup yalnızca su dengesinden yararlanılmıştır. Yüksek kısımlarda ve/veya yamaçlarda herhangi bir YGí bulunmadığından çıkarılan eşyağış haritası öncellikle mevcut YGillerle kontrol edilmiştir. Mevcut YGilerden elde edilen yıllık ortalama yağış değerleri ile eşyağış haritasından çıkarılan yağış değerlerine ait karşılaştırma Şekil 8(a)'da görülmektedir. 


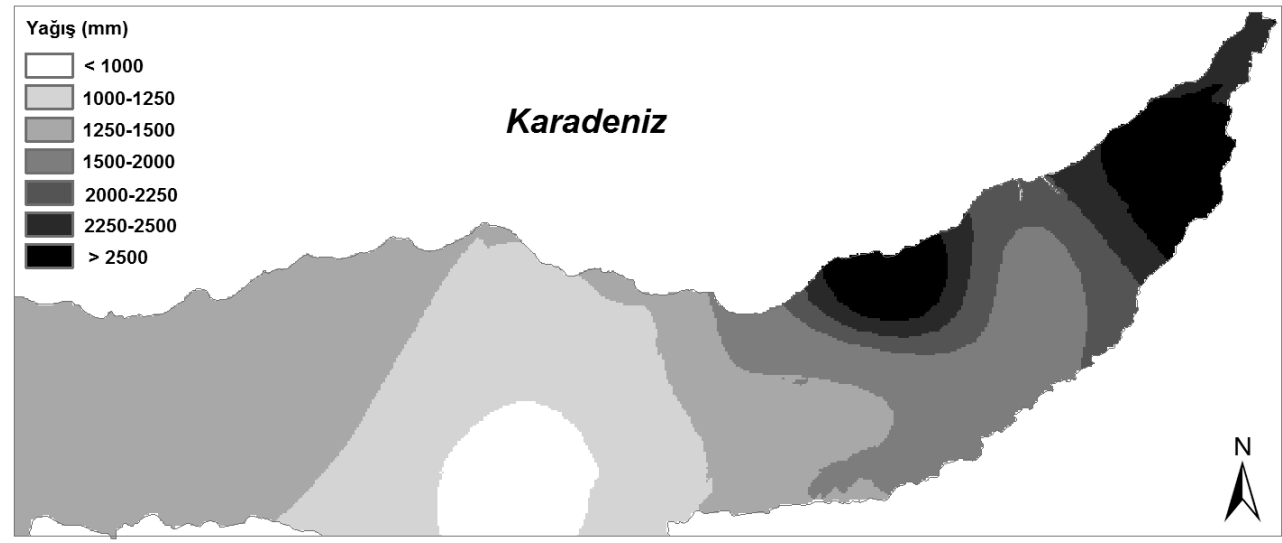

Şekil 7. Akım yüksekliği ve evapotranspirasyon haritalarından elde edilen eşyağış haritası

Şekil 8 (a)'dan görüleceği üzere, mevcut YGiller için genel olarak daha büyük tahmin değerleri bulunmuştur. Akım yüksekliği-evapotranspirasyon haritalarından elde edilen eşyağış haritasının daha büyük yağış miktarı verdiği yerler özellikle iç kesimlerdir. $\mathrm{Bu}$ durum iç kesimlerin daha az yağış aldığına dair fikri güçlendirmektedir. İç kesimlerin daha az yağış alması yazarların önceki çalışmalarında da $[21,22]$ işaret ettiği üzere kıyı şeklinin bir sonucudur. Doğu Karadeniz kıyısı doğu-batı yönlü olup kıyı şeridi burun ve koylara sahiptir. Bu topoğrafya nemi taşıyan ve hakim rüzgar yönü olan kuzeyli ve batılı rüzgarlar için doğal bir engel oluşturmaktadır.
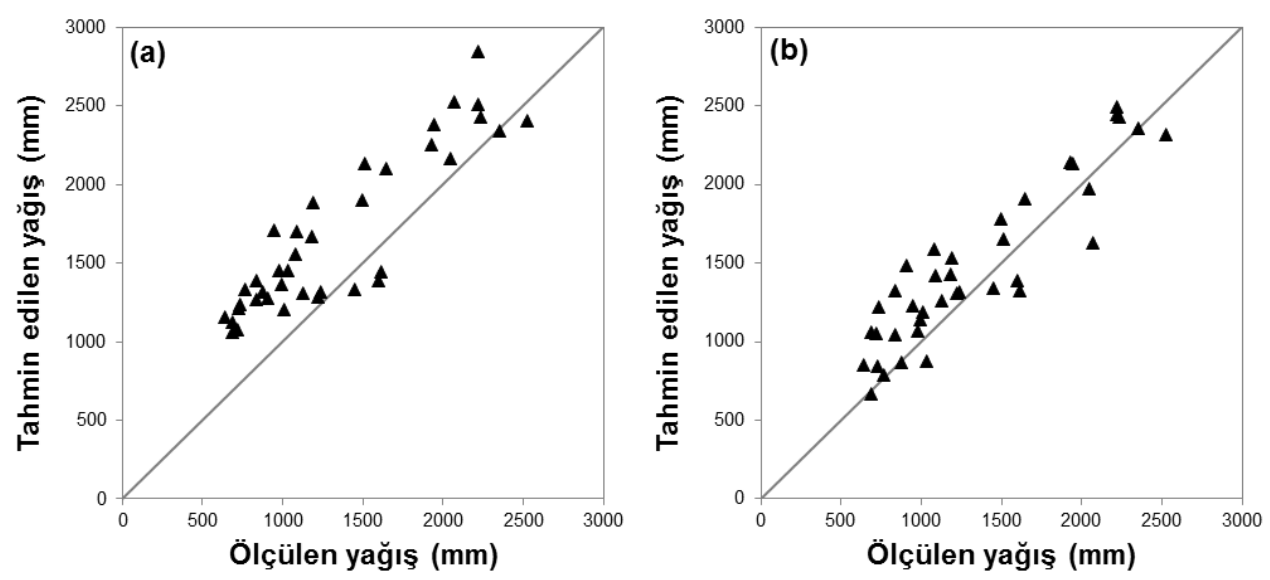

Şekil 8. Ölçüm-tahmin saçılma diyagramı (a) eşyağış haritası; (b) düzeltilmiş eşyağış haritasl

Yukarıdaki sebepler göz önüne alınarak bölgenin yağış dağılımının yeniden belirlenebilmesi için vadi içleri ve kıyı kesimi daha iyi temsil ettiği düşünülen, kıyı açısı 
değişkenini içeren regresyon denklemleri, akım yüksekliği-evapotranspirasyon haritalarından elde edilen eşyağış haritası ile birleştirilmiş ve "düzeltilmiş eşyağış haritası" olarak adlandırılmıştır. Birleştirme işlemi uygun bir Coğrafi Bilgi Sistemi (CBS) yazılımı ile yapılmıştır. Kıyı kesimi için Denklem 4(a); vadi içleri için ise Denklem 4 (b) kullanılmıştır. Kıyı kesimi boyunca seçilen noktalarda kıyı açıları bulunarak Denklem 4(a) uygulanmıştır. Öte yandan, bölgedeki akarsular denize dik konumlandıkları için her bir akarsu üzerinde/yakınında rastgele noktalar seçilerek Denklem 4(b) uygulanmıştır. Söz konusu noktalar ile kıyı kesimindeki noktalar (regresyon denklemlerinin uygulandığı noktalar) dışında kalan alanda ise akım yüksekliği-evapotranspirasyon haritalarından elde edilen eşyağış haritasının geçerli olduğu varsayılarak birleştirme işlemi yapılmıştır. Böylece kıyı ve vadi içleri regresyon denklemleri ile yamaçlar ve yüksek kısımlar ise su dengesi yaklaşımı ile temsil edilmiştir. Bir başka deyişle kıyı topoğrafyasının yağış dağılımı üzerindeki etkisinin yalnızca kıyıda değil yüksek dağ sıraları arasında kalan vadi içlerinde de temsili sağlanmıştır.

Düzeltilmiş eşyağış haritası; akım yüksekliği-evapotranspirasyon haritalarından elde edilen eşyağış haritasının, regresyon denklemleri ile birleştirilerek düzeltilmiş halidir. Mevcut YGïlerin yıllık ortalama yağış değerleri ile düzeltilmiş eşyağış haritasından çıkarılan yağış değerlerine ait çapraz doğrulama Şekil 8(b)'de verilmiştir. Şekil 8(b), vadi içleri ve kıyıların daha iyi temsil edildiğini göstermektedir. Düzeltilmiş eşyağış haritası Şekil 9'da görülmektedir. Her bir AGİ drenaj havzası için çıkarılan yıllık akış katsayıları düzeltilmiş eşyağış haritası kullanılarak yeniden hesaplanmış ve sonuçlar Şekil 10'da verilmiş̧tir. Düzeltilmiş eşyağış haritasına göre bulunan akış katsayılarının bölge ağırlıklı ortalaması yaklaşık 0.70 olarak bulunmuştur.

Bölüm 3'te Kriging ve Regresyon yöntemlerinden çıkarılmış haritalar kullanılarak bulunan akış katsayılarına göre düzeltilmiş eşyağış haritasından hesaplanan ortalama alan yağış değerleri kullanılarak bulunan akış katsayılarının bir tanesi hariç hepsi 1'den küçüktür. Akım yüksekliği-evapotranspirasyon haritalarından elde edilen eşyağış haritası kullanılarak bulunan akış katsayıları, düzeltilmiş eşyağış haritası kullanılarak bulunan akış katsayılarına göre daha küçüktür. Vadi içlerinde daha az yağış ölçüldüğü ve modelleme buna göre düzeltildiği için, ortalama alan yağışı da daha düşük bir değerde çıkmış ve dolayısıyla akış katsayılarının değeri, düzeltilmemiş eşyağış haritasından bulunan yağışlara göre hesaplanan akış katsayılarına nazaran yükselmiştir. Akış katsayısı 1'den büyük olan tek havza yaklaşık $83 \mathrm{~km}^{2}$ lik alana sahip Kömürcüler (22082) istasyonuna aittir. Bu istasyonun drenaj havzasına ait akış katsayıları her model için (Kriging, Regresyon, Akım yüksekliğievapotranspirasyon haritalarından elde edilen düzeltilmemiş eşyağış haritası ile düzeltilmiş eşyağış haritası) en büyük değeri vermiştir. Bu havzaya ait akış katsayısının büyük çıkmasının; bölgedeki en küçük drenaj alanına sahip olması ve yağış dağılımına ait yüzey haritası oluşturulurken havza çevresinde kendisine en yakın $2000 \mathrm{~mm}$.'nin üstünde yağış alan Kalkandere (32) YGİsi ile bu YGİ etrafında konumlanmış daha az yağış alan (974$1646 \mathrm{~mm}$ ) diğer YGiler arasında kurulan enterpolasyonun neden olduğu düşünülmektedir. 


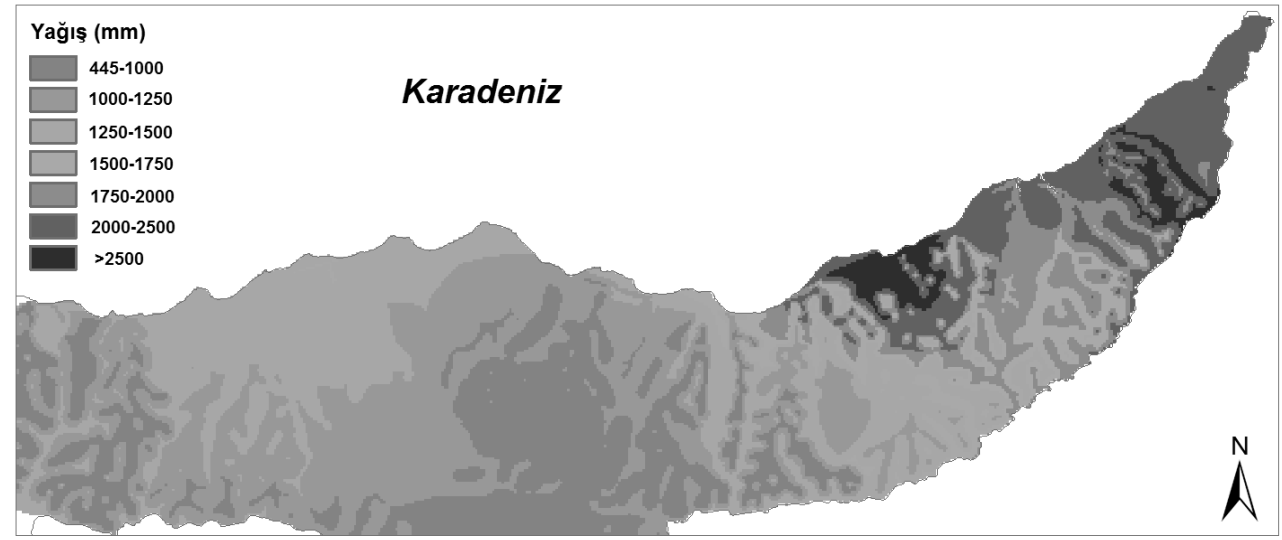

Şekil 9. Düzeltilmiş eşyağlş haritası

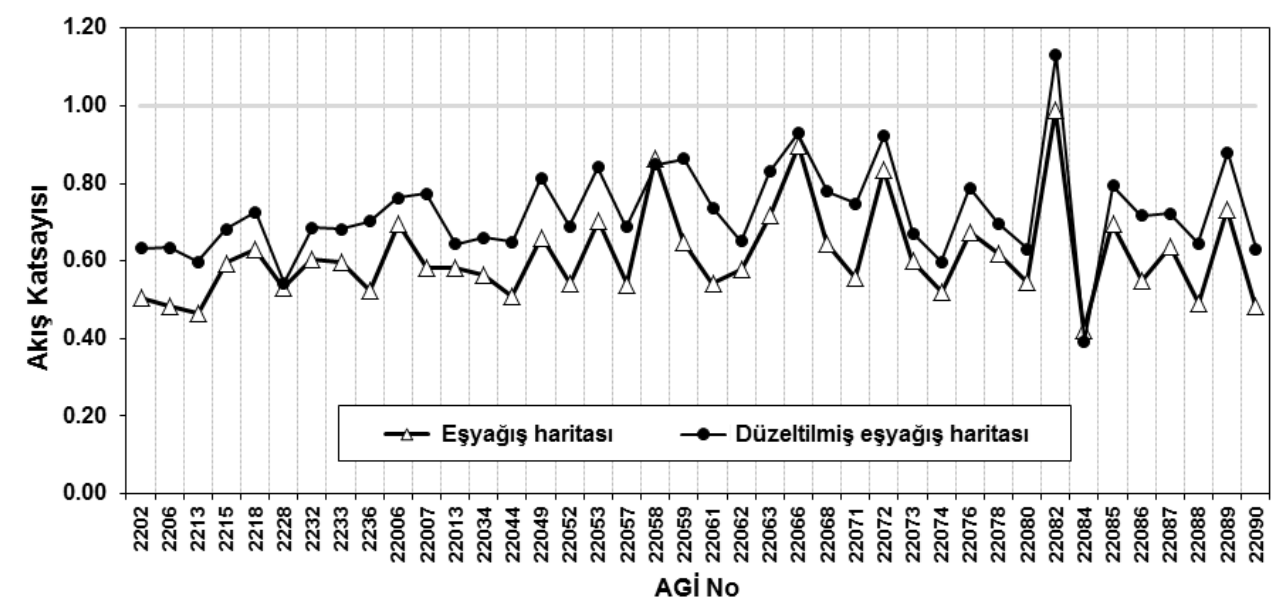

Şekil 10. AGI havzalarına ait ve düzeltilmiş eşyağış haritası kullanılarak bulunan yıllık akış katsayllart

\section{SONUÇLAR}

Bu çalışmada Doğu Karadeniz Bölgesi kıyı kısmı için yağışın alandaki dağılımının belirlenmesine çalışılmıştır. Çalışmada aşağıdaki sonuçlara ulaşılmış̧ır.

- Özellikle dağlık bölgelerde mevcut YGíler, konumları nedeniyle bölgedeki yağış dağılımını temsil etmekte yetersiz kalmaktadırlar. Mevcut YGïlerle kurulan modeller yağışı çoğu zaman olduğundan daha az tahmin etmektedirler. Nitekim bu sonuç Bozkurt vd. [33] çalışmasıyla da doğrulanmaktadır. Söz konusu çalışmada kurulan iklim modeli sonuçları ile nokta ölçümleri arasındaki farkın; yüksek kısımlarda 
gözlem istasyonun bulunmamasından kaynaklandığı ve mevcut YGilerle yağış dağılımının belirlenmesinin iyi sonuç vermeyeceği belirtilmektedir.

- Günümüzde yağış dağılımının belirlenmesinde sıkça kullanılan Kriging vb. jeoistatiksel yöntemlerin doğruluğu özellikle karmaşık topoğrafyaya ve/veya yetersiz sayıda gözlem istasyonuna sahip bölgeler için akış katsayısı vb. bir yöntemle kontrol edilmelidir.

- Yüksek kesimlerde ve/veya yamaçlarda YGİ mevcut değilse su dengesi yaklaşımı ile daha doğru bir eşyağış haritasına ulaşmak mümkündür. Ancak elde edilecek haritanın çalışma bölgesinin yă̆ı̧ karakteristiğine göre düzeltilmesi gerekli olabilir.

- Doğu Karadeniz Bölgesi kıyı kesimi için çıkarılan düzeltilmiş eşyağış haritasına dayanarak elde edilen akış katsayılarının bölge ağırlıklı ortalaması yaklaşık 0.70 olarak bulunmuştur.

- Çalışma bölgesi için eşyağış haritası çıkarımında kullanılmak üzere elde edilen akım yüksekliği ve muhtemel evapotranspirasyon haritası; bölgede bu türde ölçümü bulunmayan noktalar açısından bakıldığında, kullanıcıya faydalı olabilecek niteliktedir. Bu çalışmada elde edilen haritalar, bölge için mevcut haritalara göre kullanıcıya daha gerçekçi sonuçlar sunabilecektir.

\section{Semboller}

$\begin{array}{ll}A & \text { Kıyı açısı } \\ M E T & \text { Muhtemel evapotranspirasyon } \\ P E T & \text { Potansiyel evapotranspirasyon } \\ Y & \text { Enlem } \\ Z^{*}\left(x_{0}\right) & \text { Tahmin noktasındaki yağış değeri } \\ Z^{*}\left(x_{i}\right) & \text { Çevre noktalardaki yağış değerleri } \\ Z(x) & x \text { noktasındaki yağış değeri } \\ Z(x+h) & x+h \text { noktasındaki yağış değeri } \\ \beta & \text { Regresyon katsayısı } \\ \gamma & \text { Yarıvaryogram } \\ \lambda_{i} & \text { Ağırlık } \\ \mu & \text { Hata terimi, Lagrange sabiti }\end{array}$

\section{Teşekkür}

Yazarlar çalışmaya desteğinden dolayı TÜBİTAK'a ve makalenin gelişmesine katkıda bulunan hakemlere teşekkür eder. 
Ölçümleri Az Olan Kıyı Bölgelerinde Yağışıı Yerel Dağılımının ...

\section{Kaynaklar}

[1] Daly C., Neilson R.P. ve Phillips D.L., A statistical-topographic model for mapping climatological precipitation over mountainous terrain, Journal of Applied Meteorology, 33, 2, 140-158, 1994.

[2] Tabios III, G.Q. ve Salas, J.D., A comparative analysis of techniques for spatial interpolation of precipitation, Water Resources Bulletin, 21, 3, 265-380, 1985.

[3] Pardo-Iguzquiza, E., Comparison of geostatistical methods for estimating the areal average climatological rainfall mean using data on precipitation and topography, International Journal of Climatology, 18, 1031-104, 1998.

[4] Hevesi, J.A., Istok, J.D. ve Flint, A.L., Precipitation estimation in mountainous terrain using multivariate geostatistics, Part I: structural analysis, Journal of Applied Meteorology, 31, 661-676, 1992a.

[5] Hevesi, J.A., Istok, J.D. ve Flint, A.L, Precipitation estimation in mountainous terrain using multivariate geostatistics. Part II: isohyetal maps, Journal of Applied Meteorology, 31, 677-688, 1992b.

[6] Dirks K.N., Hay J.E., Stow C.D. ve Harris, D., High-resolution studies of rainfall on Norfolk Island, Part II: interpolation of rainfall data, Journal of Hydrology, 208, 3-4, 187-193, 1998.

[7] Goovaerts, P., Geostatistical approaches for incorporating elevation into the spatial interpolation of rainfall, Journal of Hydrology, 228, 113-129, 2000.

[8] Lloyd, C. D., Assessing the effect of integrating elevation data into the estimation of monthly precipitation in Great Britain, Journal of Hydrology, 308, 128-150, 2005.

[9] Basistha A., Arya D.S. ve Goel, N.K., Spatial distribution of rainfall in Indian Himalayas-A case study of Uttarakhand region, Water Resources Management, 22, 1325-1346, 2008.

[10] Hastenrath, S. L., Rainfall distribution and regime in Central America, Theoretical and Applied Climatology, 15, 3, 201-241, 1967.

[11] Park, J.I. ve Singh, V.P., Temporal and spatial characteristics of rainfall in the Nam River dam basin of Korea, Hydrological Processes, 10, 1155-1171, 1996.

[12] Baker, D.R., Lynn, B.H., Boone, A., Tao, W.K. ve Simpson, J., The influence of soil moisture, coastline curvature, and land-breeze circulations on sea-breeze-initiated precipitation, Journal of Hydrometeorology, 2, 2, 193-21, 2001.

[13] Marquinez, J., Lastra, J. ve Garcia, P., Estimation models for precipitation in mountainous regions: the use of GIS and multivariate analysis, Journal of Hydrology, $270,1-11,2003$.

[14] Naoum, S. ve Tsanis, I. K., Orographic precipitation modeling with multiple linear regression, Journal of Hydrologic Engineering, 9, 2, 79-102, 2004. 
[15] Bostan P. A. ve Akyurek Z., Exploring the mean annual precipitation and temperature values over Turkey by using environmental variables, Poster presentation, ISPRS Joint Workshop: Visualization and Exploration of Geospatial Data, Germany, 2007.

[16] Ranhao S., Baiping Z. ve Jing, T., A multivariate regression model for predicting precipitation in the Daqing mountains, Mountain Research and Development, 28, 3-4, 318-325, 2008.

[17] Sun, W., Zhu, Y., Huang, S. Ve Guo, C., Mapping the mean annual precipitation of China using local interpolation techniques, Theoretical and Applied Climatology, 119, 1, 171-180, 2015.

[18] Fekete, B. M., Vörösmarty, C. J. ve Grabs, W., Global composite runoff fields based on observed river discharge and simulated water balances, Documentation for UNHGRDC Composite Runoff Fields, v.1.0, Global Runoff Data Center, Koblenz, Germany, 2000.

[19] Adam, J. C., Clark, E. A. ve Lettenmaier, D. P., Correction of global precipitation products for orographic effects, Journal of Climate, 19, 15-38, 2006.

[20] Xia, Y., Adjustment of global precipitation data for orographic effects using observed annual streamflow and the LaD model, Journal of Geophysical Research, 113, D04106, 2008.

[21] Eris E. ve Ağıralioğlu, N., Effect of coastline configuration on precipitation distribution in coastal zones, Hydrological Processes, 23, 3610-3618, 2009.

[22] Eriş, E. ve Ağıralioğlu, N., Kıyı alanlarında kıyı şeklinin yağış dağılımına etkisi, Bildiriler Kitabı, 6. Ulusal Hidroloji Kongresi, 428-438, Denizli, 2010.

[23] SHODB (Seyir Hidrografi ve Oşinografi Dairesi Başkanlığı), Karadeniz Meteoroloji Atlası, İstanbul; 39, 1991.

[24] Agiralioglu, N., Cigizoglu, H.K., Yilmaz, L., Coskun, H.G., Aksoy, H., Toprak, Z.F., Eris, E., Alganci, U., Andic, G., Usta, G., Besiktas, M., Ulken, I., Akım ölçümleri olmayan akarsu havzalarında teknik hidroelektrik potansiyelin belirlenmesi, 188, TüBİTAK, Proje No 106M043, 2009.

[25] Coulibaly, M. ve Becker, S., Spatial interpolation of annual precipitation in South Africa- Comparison and evaluation of methods, Water International, 32 (3), 494-502, 2007.

[26] Vasiliades, L. ve Loukas, A., Precipitation spatial interpolation methods assessment in Pinios River Basin, Greece, Proceedings of the 11th International Conference on Enviromental Sicence and Technology, A1523-1530, 2009.

[27] Kaya, N., Sarımsaklı akarsuyuna olan beslenim miktarının akım gözlemlerinden faydalanarak hesaplanması, DSİ Teknik Bülten, 101, 1-17, 2006.

[28] Akın M. ve Akın, G., Suyun önemi, Türkiye'de su potansiyeli, su havzaları ve su kirliliği, Ankara Üniversitesi Dil ve Tarih-Coğrafya Fakültesi Dergisi, 47, 2, 105-118, 2007. 
Ölçümleri Az Olan Kıyı Bölgelerinde Yağışın Yerel Dağıllmının ...

[29] Huang, W.C. ve Yang, F.T, Streamflow estimation using Kriging, Water Resources Research, 34, 6, 1599-1608, 1998.

[30] Turc, L., Le Bilan D'eau des sols. Relation entre les precipitation, l'evaporation et l'ecoulement, Annales Agronomique, 5, 491- 595, 1954.

[31] Pike, J. G., Estimation of annual run-off from meteorological data in tropical climate, Journal of Hydrology, 2, 2, 116-123, 1964.

[32] Allen, R.G., Pereira, L.S., Raes, D., Smith, M., Crop evapotranspiration: guidelines for computing crop water requirements, Food and Agriculture Organization of the United Nations, Rome, 1998.

[33] Bozkurt, D., Turuncuoglu, U., Sen, O.L., Onol, B., Dalfes, H.N., Downsclaed simulations of the ECHAM5, CCSM3 and HadCM3 global models for the eastern Mediterranean-Black Sea region: evaluation of the reference period, Climate Dynamics, 39, 207-225, 2012. 